\title{
Addressing organ shortages: progress in donation after circulatory death for liver transplantation
}

Jordan J. Nostedt, MD, MSc

A.M. James Shapiro, MD, PhD

Darren H. Freed, MD, PhD

David L. Bigam, MD, MSc

Accepted July 24, 2019

\section{Correspondence to:}

\section{D.L. Bigam}

Department of Surgery

University of Alberta

8440 - 112 ST NW

Edmonton AB T6G 2B7

david.bigam@albertahealthservices.ca

DOI: $10.1503 /$ cjs.005519

\begin{abstract}
Reducing wait list mortality among patients awaiting liver transplantation remains a substantial challenge because of organ shortage. In efforts to expand the donor pool there has been a trend toward increased use of donation after circulatory death (DCD) liver grafts. However, these marginal grafts are prone to higher complication rates, particularly biliary complications. In addition, many procured DCD livers are then deemed unsuitable for transplant. Despite these limitations, DCD grafts represent an important resource to address the current organ shortage, and as such there are research efforts directed toward improving the use of and outcomes for transplantation of these grafts. We review the current progress in DCD liver transplantation.
\end{abstract}

La réduction du nombre de personnes en attente d'une greffe de foie qui décèdent avant la transplantation demeure un défi important en raison de la pénurie d'organes. On remarque actuellement une tendance à la hausse dans l'utilisation de greffons de foie provenant de don après décès circulatoire (DDC) dans le but d'élargir le bassin de donneurs. Ces greffons marginaux sont toutefois associés à des taux de complications plus élevés, particulièrement pour ce qui est des complications biliaires. De plus, de nombreux foies obtenus à la suite d'un DDC sont jugés inadmissibles à la greffe. Malgré ces restrictions, les greffons provenant de DDC représentent une importante ressource pour atténuer la pénurie d'organes. Des initiatives de recherche sont donc actuellement en cours dans le but d'améliorer leur taux d'utilisation et les issues des transplantations. Nous analysons ici l'état actuel des progrès pour les transplantations de foie provenant de DDC. iver transplant remains the definitive treatment for end-stage liver disease. In 2017, 182 Canadians either died while on the wait list or became too sick to undergo the operation. ${ }^{1}$ A CMAJ article by Shemie highlighted the current trend toward increasing use of donation after circulatory death (DCD) grafts to address organ shortages. ${ }^{2}$ In 2017, 53 Canadians underwent liver transplant with DCD grafts, the highest number to date. ${ }^{1}$

Donation after circulatory death differs from the more common donation after neurological death (DND). Before procurement, DCD livers are exposed to a period of warm ischemia time (WIT) after cardiopulmonary arrest in which the organ is no longer perfused; in DND livers, perfusion persists right up until the moment of procurement in the operating room. As a result, higher complication rates persist. ${ }^{3}$ Although DCD liver transplants have increased in recent years, in $201715 \%$ of the DCD liver grafts procured in Canada were subsequently discarded before transplantation. ${ }^{1}$ The high discard rate of the grafts and higher complication rates induced by WIT suggest that the current preservation strategy of static cold storage (SCS) is not well tolerated by these injured grafts. We present a brief overview of DCD liver transplant outcomes and review the progress in improving DCD outcomes (e.g., donor selection, use of thrombolytic medications, machine perfusion preservation strategies). 


\section{LITERATURE SEARCH}

We searched PubMed using the Medical Subject Headings "donation after circulatory death" and "liver transplant." This search yielded 211 articles. Of these, we reviewed those that matched best. Relevant articles from the references listed in select articles were also reviewed. When possible, we discussed the highest level of evidence in randomized controlled trials; however, this level of evidence was limited and, therefore, observational data were also reviewed.

\section{CURRENT OUTCOMES IN DCD LIVER TRANSPLANTATION}

A 2011 meta-analysis that included 489 DCD and 4455 DND recipients revealed a 1.6-fold increase in 1-year mortality and a 2.1-fold increased risk of 1-year graft failure for DCD grafts compared with DND. ${ }^{4}$ More recently, however, a meta-analysis including more than 12000 patients found no difference in patient or graft survival when comparing DCD and DND liver transplants. ${ }^{5}$

The same improvement has not been observed regarding ischemic cholangiopathy (IC), defined as the occurrence of multiple intrahepatic strictures in the absence of hepatic artery thrombosis or stenosis. ${ }^{6}$ Ischemic cholangiopathy is 2.5 times more likely in DCD liver grafts than DND. ${ }^{5}$ While hepatocytes receive dual blood supply from both the portal vein and hepatic artery, biliary cells receive only arterial blood. ${ }^{7}$ Both DND and DCD livers demonstrate loss of intraluminal biliary epithelium as a result of procurement and preservation; however, only those with significant damage to the deep peribiliary plexus, the site of progenitor cells for regeneration of the biliary ducts show an increased risk of IC. ${ }^{8}$ Thus it has been hypothesized that IC develops from an impaired ability to regenerate biliary cells after revascularization secondary to peribiliary vascular plexus injury in DCD grafts. ${ }^{8}$

Ischemic cholangiopathy leads to higher rates of graft failure, longer hospital admissions, increased biliary procedures, retransplantation and overall increased health care costs. ${ }^{9}$ Improving IC rates in DCD transplants remains a substantial challenge for ongoing research efforts.

\section{DONOR FACTORS AFFECTING DCD LIVER TRANSPLANT OUTCOMES}

\section{Donor age}

Older donor age has been identified consistently as a risk factor for complications in DCD liver transplantation. ${ }^{10}$ Donor age older than 50 years has been shown to predict risk for $\mathrm{IC}^{11}$ and graft failure. ${ }^{10}$ However, when other risk factors were minimized, Schlegel and colleagues found no difference in biliary or overall complications in DCD liver grafts between cohorts older or younger than 60 years. ${ }^{12}$
They concluded that older DCD donors may provide viable grafts when other risk factors are mitigated.

\section{Donor obesity}

Rising obesity rates have resulted in increasing numbers of donors with steatosis. ${ }^{13}$ In DCD liver grafts from obese donors, there has been poor tolerance of SCS evidenced by worse transplant outcomes. ${ }^{13}$ Elevated body mass index (BMI) has been associated with increased IC as well as worse graft and patient survival. ${ }^{10-12,14}$ Liver steatosis leads to lower adenosine triphosphate (ATP) levels, microcirculatory dysfunction, increased inflammation and reactive oxygen species production with ultimately more severe ischemia reperfusion injury. ${ }^{13}$ Improving outcomes of this expanding subset of donor livers has become an area of keen research interest for machine perfusion.

\section{Warm ischemia time}

For DCD procurement, the WIT cut-off in many centres is 30 minutes. Both graft failure and IC have been linked to prolonged WIT. ${ }^{10,14,15}$ Tun-Abraham and colleagues ${ }^{16}$ evaluated their single-centre series, dividing their cohort into early (July 2006 to June 2011) and late (July 2011 to July 2016) periods. The late group showed reduced times from incision to arterial cannulation and organ flush. ${ }^{16}$ This was accompanied by a statistically significant reduction in IC for the late group. ${ }^{16}$ These improvements were attributed to a learning curve, suggesting procurements done by staff experienced in DCD could improve outcomes. ${ }^{16}$ In addition a meta-analysis looking at DCD liver transplant outcomes between those who had life support withdrawn in the intensive care unit compared with the operating room found that both graft survival and rate of IC were improved by withdrawal of life support in the operating room. ${ }^{17}$ This varies by institution; however, a shift in policies to allow withdrawal of life support in the operating room may contribute to improved outcomes.

\section{Cold ischemia time}

Cold ischemia time (CIT) has been identified as a significant risk factor for poor outcomes in DCD liver transplantation. ${ }^{18,19}$ In order to reduce the risk of IC and graft failure, it has been suggested that CIT be limited to less than 10 hours. ${ }^{18}$ Others suggest even more strict time limits of less than 9 hours of total ischemia time. ${ }^{11}$

\section{THROMBOLYTIC MEDICATIONS DURING DCD TRANSPLANTATION}

The addition of thrombolytic medications has received recent research interest (Table 1). Tissue plasminogen activator ( $\mathrm{tPA})$ was injected via the hepatic artery on the back 
table based on the hypothesis that microthrombi from stasis during WIT led to damaged peribiliary vasculature and ultimately contributed to IC. ${ }^{20}$ In this initial study, 22 DCD transplants were carried out with the tPA protocol, 2 (9\%) recipients developed IC, which is lower than previously reported; however, excessive bleeding was encountered in $14(64 \%)$ of the 22 recipients. ${ }^{20}$ Subsequent studies modified the tPA protocol and injected the drug via the hepatic artery after venous reperfusion in the recipient. ${ }^{21,24} \mathrm{~A}$ description of the approaches for tPA administration in DCD liver transplant has been described in detail elsewhere. ${ }^{25}$ The more recent studies using tPA showed improved 1- and 3-year patient and graft survival and a significant reduction in IC relative to controls. ${ }^{21,24}$ These studies did not show the same increased transfusion requirement previously described by Hashimoto and colleagues. ${ }^{20}$ A detailed meta-analysis that included 249 patients in the tPA group and 178 patients not receiving tPA showed a significant reduction in IC and retransplant rates for the tPA group without increased transfusion requirements, leading the authors to conclude that $\mathrm{tPA}$ provides an advantage for preventing IC. ${ }^{25}$ Further supporting the use of tPA protocols for DCD liver grafts is the recent demonstration of cost savings with this intervention. ${ }^{26}$

\section{Progress In EX-Situ MACHINE PERfUSion}

The higher incidence of biliary complications and graft failure with DCD grafts has been attributed to the dam- age incurred during WIT and subsequent SCS. Increased research interest in machine perfusion has led to the clinical use of this modality as an alternative preservation strategy (Table 2). Machine perfusion is classified broadly by the temperature of the perfusate: hypothermic machine perfusion (HMP), subnormothermic machine perfusion (SNMP), and normothermic machine perfusion (NMP).

\section{Hypothermic machine perfusion}

Providing oxygen in the perfusate at subphysiologic flow rates and temperatures allows for improved mitochondrial and endothelial protection. ${ }^{36}$ In a large animal model, DCD livers undergoing HMP showed lower alanine aminotransferase (ALT) and aspartate aminotransferase (AST) levels, ${ }^{37}$ and improved preservation of the biliary microvasculature relative to SCS. ${ }^{38}$ There were also significant improvements in ATP levels, bile production, bile composition and lactate levels relative to those transplanted after SCS. ${ }^{28,39}$ Several clinical studies using HMP have now been completed (Table 2), the largest of which compared 50 DCD livers treated with HMP to 50 DCD SCS livers and 50 DND controls. There was a significantly lower rate of IC relative to the DCD SCS group with increased survival and reduced retransplant rate at 1 year. ${ }^{27}$ At 5 -year follow-up, graft survival was $94 \%$ compared with $78 \%$ in DCD grafts without HMP. ${ }^{30}$

A criticism of this modality is that it remains difficult to assess liver function during perfusion, as metabolic

\begin{tabular}{|c|c|c|c|c|}
\hline Study & No. of DCD patients & Thrombolytic protocol & Thrombolytic dose & Summary of key outcomes \\
\hline Hashimoto et al. ${ }^{20}$ & $n=22$ & $\begin{array}{l}\text { tPA injected in the hepatic artery on } \\
\text { the back table }\end{array}$ & $\begin{array}{l}\text { tPA protocol dose }(n=12) \text { : } \\
0.5 \mathrm{mg} / 100 \mathrm{~g} \text { graft weight } \\
\text { tPA reduced dose for high risk } \\
\text { of bleeding }(n=10) \text { : } \\
0.2-0.4 \mathrm{mg} / 100 \mathrm{~g} \text { graft weight }\end{array}$ & $\begin{array}{c}\text { Graft survival at } 1 \text { and } 3 \text { years } \\
\text { was } 81 \% \text {. } \\
\text { Ischemic cholangiopathy } \\
\text { developed in } 9 \% \text { while } 64 \% \text { had } \\
\text { excessive bleeding. }\end{array}$ \\
\hline Seal et al. ${ }^{21}$ & $\begin{array}{c}\text { tPA } n=85 \\
\text { no tPA } n=33\end{array}$ & $\begin{array}{c}\text { Centre specific: tPA injected into the } \\
\text { hepatic artery at the time of portal } \\
\text { vein anastomosis or at the time of } \\
\text { hepatic artery anastomosis }\end{array}$ & $\begin{array}{l}\text { Centre specific: tPA } 2 \mathrm{mg} \text { or } \\
100 \mathrm{mg} / \mathrm{kg} \text { donor weight }\end{array}$ & $\begin{array}{l}\text { tPA use improved 1- and 3-year } \\
\text { patient and graft survival, } \\
\text { reduced ischemic cholangiopathy } \\
\text { and did not increase the risk of } \\
\text { bleeding. }\end{array}$ \\
\hline Pietersen et al. ${ }^{22}$ & $\begin{array}{l}\text { Urokinase } n=63(17 \\
\text { DCD }) \\
\text { No urokinase } n=122 \\
\text { (28 DCD) }\end{array}$ & $\begin{array}{l}\text { Urokinase injected into hepatic artery } \\
\text { on back table immediately before } \\
\text { implantation }\end{array}$ & Urokinase $250000 \mathrm{IU}$ & $\begin{array}{l}\text { Urokinase use did not lower } \\
\text { ischemic cholangiopathy rates. } \\
\text { There was no difference in graft } \\
\text { survival and no increase in blood } \\
\text { transfusion requirements. }\end{array}$ \\
\hline Kubal et al. ${ }^{23}$ & $\begin{array}{c}\text { tPA } n=30 \\
\text { no tPA } n=61 \text { (historic } \\
\text { controls) }\end{array}$ & $\begin{array}{c}\text { tPA injected into hepatic artery: tPA } \\
100 \mathrm{mg} \text { mixed with } 1 \mathrm{~L} \text { normal saline } \\
\text { initial flush }(900 \mathrm{~mL}) \text {, then additional } \\
100 \mathrm{~mL} \text { of tPA solution following } \\
\text { organ flush with HTK }\end{array}$ & tPA total dose $100 \mathrm{mg}$ & $\begin{array}{l}\text { No difference in overall survival. } \\
\text { tPA flush resulted in a significant } \\
\text { reduction in ischemic cholangi- } \\
\text { opathy without increased } \\
\text { bleeding risk. }\end{array}$ \\
\hline Bohorquez et al. ${ }^{24}$ & $\begin{array}{c}\text { tPA } n=100 \\
\text { no tPA } n=38 \text { (historic } \\
\text { controls) }\end{array}$ & $\begin{array}{l}\text { tPA injected into hepatic artery } \\
\text { immediately after portal vein } \\
\text { reperfusion }\end{array}$ & tPA $2 \mathrm{mg}$ & $\begin{array}{l}\text { tPA use improved 1- and 3-year } \\
\text { graft survival. } \\
\text { There was no statistically } \\
\text { significant difference in ischemic } \\
\text { cholangiopathy and no increased } \\
\text { bleeding risk. }\end{array}$ \\
\hline
\end{tabular}


Table 2. Clinical studies using ex-situ machine perfusion that include donation after circulatory death grafts

\begin{tabular}{|c|c|c|c|c|c|c|c|}
\hline Study & No. of patients & $\begin{array}{l}\text { Perfusion } \\
\text { temperature }\end{array}$ & $\begin{array}{l}\text { Median } \\
\text { WIT, min }\end{array}$ & $\begin{array}{l}\text { Median } \\
\text { CIT, hr }\end{array}$ & $\begin{array}{c}\text { Perfusion } \\
\text { duration, } \\
\mathrm{hr}\end{array}$ & Outcome measures & Key findings \\
\hline Dutkowski et al. ${ }^{27}$ & $\begin{array}{c}\text { HMP: } 25 \text { DCD } \\
\text { SCS: } 50 \text { DCD historic } \\
\text { controls }\end{array}$ & HMP & 36 & 6.6 & 2 & $\begin{array}{c}\text { AST, ALT, bilirubin, INR, } \\
\text { early allograft } \\
\text { dysfunction, ischemic } \\
\text { cholangiopathy, hospital/ } \\
\text { ICU stay, graft loss, } \\
\text { 1-year graft survival }\end{array}$ & $\begin{array}{c}\text { HMP-treated livers had a } \\
\text { significant decrease in peak } \\
\text { ALT, ischemic cholangiopathy } \\
\text { and improved 1-year graft } \\
\text { survival. }\end{array}$ \\
\hline Schlegel et al. ${ }^{30}$ & $\begin{array}{c}\text { HMP: } 50 \text { DCD } \\
\text { SCS: } 50 \text { DCD historic } \\
\text { controls } \\
\text { SCS: } 50 \text { DND historic } \\
\text { controls }\end{array}$ & HMP & 31 & - & - & $\begin{array}{l}\text { INR, ALT, hospital/ICU } \\
\text { length of stay, } \\
\text { postoperative } \\
\text { complications, ischemic } \\
\text { cholangiopathy }\end{array}$ & $\begin{array}{l}\text { Significantly improved 5-year } \\
\text { graft survival in HMP group. } \\
\text { HMP group also had less } \\
\text { ischemic cholangiopathy but } \\
\text { with longer hospital stays. }\end{array}$ \\
\hline Ravikumar et al. ${ }^{31}$ & $\begin{array}{c}\text { NMP: } 20 \\
\text { (4 DCD) } \\
\text { SCS: } 40 \text { (8 DCD) } \\
\text { historic controls }\end{array}$ & NMP & 21 & 8.9 & 9.3 & $\begin{array}{l}\text { 30-day graft survival, } \\
\text { AST, ALP, bilirubin, INR, } \\
\text { patient and graft survival, } \\
\text { 6-month graft function, } \\
\text { length of stay }\end{array}$ & $\begin{array}{l}\text { Lower peak AST in the first } 7 \\
\text { postoperative days in the } \\
\text { NMP group. No difference in } \\
\text { graft or patient survival. No } \\
\text { difference in length of ICU or } \\
\text { hospital stay. }\end{array}$ \\
\hline Nasralla et al. ${ }^{34}$ & $\begin{array}{c}\text { NMP } 170 \text { (63 DCD) } \\
\text { SCS } 164 \text { (60 DCD) } \\
\text { RCT }\end{array}$ & NMP & 21 & 7.8 & 9.1 & $\begin{array}{l}\text { Peak AST, organ discard } \\
\text { rate, post-reperfusion } \\
\text { syndrome, primary } \\
\text { nonfunction, early } \\
\text { allograft dysfunction, } \\
\text { length of hospital/ICU } \\
\text { stay, need for renal } \\
\text { replacement therapy, } \\
\text { 6-month cholangiopathy, } \\
1 \text { year patient and graft } \\
\text { survival }\end{array}$ & $\begin{array}{l}\text { NMP group showed lower } \\
\text { peak AST, less early allograft } \\
\text { dysfunction and lower discard } \\
\text { rates relative to SCS. These } \\
\text { findings were more } \\
\text { pronounced in the DCD } \\
\text { subgroup. There was no } \\
\text { statistically significant } \\
\text { difference in biliary outcomes, } \\
\text { hospital//CU stay or patient } \\
\text { and graft survival. }\end{array}$ \\
\hline Bral et al. ${ }^{35}$ & $\begin{array}{c}\text { NMP: } 17 \text { (4 DCD) } \\
\text { NMP following SCS: } \\
26 \text { (6 DCD) }\end{array}$ & NMP & $\begin{array}{l}\text { NMP: } 20 \\
\text { SCS + NMP: } \\
21\end{array}$ & $\begin{array}{l}\text { NMP: } 3.2 \\
\text { SCS }+ \\
\text { NMP: } 6\end{array}$ & 8.1 & $\begin{array}{l}\text { 90-day and 6-month } \\
\text { patient and graft survival, } \\
\text { AST, ALT, ALP, bilirubin, } \\
\text { INR, early allograft } \\
\text { dysfunction, 6-month bili- } \\
\text { ary and vascular } \\
\text { complications }\end{array}$ & $\begin{array}{l}\text { No difference in graft or } \\
\text { patient survival. Biliary } \\
\text { complications between } \\
\text { groups were equivalent. }\end{array}$ \\
\hline & & & & t & & DCD = donation after circ & $\begin{array}{l}y \text { death; } \mathrm{DND}=\text { donation after } \\
\mathrm{MP}=\text { normothermic machine }\end{array}$ \\
\hline
\end{tabular}


activity is minimized under hypothermic conditions. Thus, defining criteria of organs suitable for transplantation will be an important goal if this modality is to be used more widely in clinical practice. Hypothermic machine perfusion has shown benefit following periods of SCS, which in the Canadian population, where organs are being transported long distances, would allow for implementation without substantial alteration of current procurement strategies. An ongoing randomized trial (NCT02584283) will shed further light on the potential of this technology.

\section{Subnormothermic machine perfusion and controlled oxygenated rewarming}

In animal studies, controlled oxygenated rewarming (COR) with gradual rewarming followed by perfusing at subnormothermic temperatures $\left(20-21^{\circ} \mathrm{C}\right)$ was superior to HMP and SCS, with improved serum enzyme levels, portal vein resistance, bile production and histological injury scores. ${ }^{40}$ It also demonstrated improved ATP recovery relative to NMP or SCS. ${ }^{41}$ The first clinical series involved 6 patients who underwent COR for 90 minutes following SCS and were compared with a historic cohort. Controlled oxygenated rewarming had a statistically significant reduction in peak AST, and at 6-month follow-up all patients had normal liver function tests. ${ }^{42}$ However this series did not include any DCD grafts. There are limited data regarding SNMP or COR for DCD liver grafts. In a series of perfusions consisting of 5 discarded DCD human livers, SNMP demonstrated increased ATP levels and clearance of lactate during 3 hours of SNMP. ${ }^{43}$ More evidence is required in order to make any conclusions regarding the use of SNMP/COR for DCD liver grafts.

\section{Normothermic machine perfusion}

Normothermic machine perfusion aims to recreate physiologic conditions to recover and assess liver grafts before transplantation. Large animal models have demonstrated lower transaminase levels, improved lactate clearance and better histologic preservation of hepatocytes relative to SCS. ${ }^{44,45}$ In addition, NMP has shown improved preservation of biliary endothelial regeneration capacity, which is hypothesized to prevent the development of IC. ${ }^{44}$ It is also being investigated as a modality to "de-fat" livers from obese donors. ${ }^{13}$ However, consensus on the optimal NMP perfusate composition, circuit set-up, and viability criteria have not yet been reached. ${ }^{46}$ Nonetheless, following the positive results of animal studies, multiple clinical trials have now been completed (Table 2). In the first phase- 1 clinical trial, 20 livers (4 DCD) were preserved using NMP and compared with 40 (8 DCD) controls preserved with SCS. The NMP group demonstrated significantly lower median peak AST levels in the first 7 days posttransplant (417 IU [interquartile range (IQR) 84-4681]) relative to the SCS controls (SCS 902 [IQR 218-8786], $p=0.03$ ), with $100 \% 30$-day graft survival in the NMP group. ${ }^{31}$ These results led the authors to conclude that this technology was safe and had the potential to increase the number of quality transplantable livers. This study was followed up by the publication of 2 North American phase-1 trials similar in design to that of Ravikumar and colleagues. ${ }^{31}$ Selzner and colleagues compared 10 livers (2 DCD) preserved with NMP to 30 (6 DCD) liver grafts preserved with SCS,32 and Bral and colleagues compared 9 grafts (4 DCD) preserved with NMP to 30 (8 DCD) grafts preserved with SCS. ${ }^{33}$ Though neither of these 2 studies was able to show the same statistically significant reduction in transaminase levels, there was no difference in graft survival $^{32,33}$ or ischemic cholangiopathy. ${ }^{33}$ The study by Bral and colleagues demonstrated higher overall transaminase levels than the other 2 phase-1 clinical trials, which was attributed to there being a greater proportion of DCD grafts in their study. There was also a statistically significant increase in the median length of stay in the intensive care unit (ICU) for the NMP group relative to SCS controls (16 d v. $4 \mathrm{~d}, p=0.004)$. ${ }^{33}$ Taken together, these phase- 1 trials established the safety and feasibility of NMP leading to commencement of the first randomized control trial. Given the low numbers of DCD grafts in these initial trials and the results of Bral and colleagues, the capacity to improve the quality of DCD grafts using NMP remains to be determined.

In the first randomized control trial, Nasralla and colleagues reported data on 170 livers (63 DCD) and 164 livers (64 DCD) that were randomized to NMP and SCS, respectively. There was no significant difference in 1-year graft or patient survival; however, there was a statistically significant reduction in peak AST in the NMP group compared with the SCS group (median 484 [IQR 406-578] v. median 973 [IQR 795-1192], $p<0.001$ ), and early allograft dysfunction was also reduced to $10.1 \%$ compared with $29.9 \%$ for SCS. ${ }^{34}$ Another important finding of this study was a lower organ discard rate for the NMP preserved livers $(11.7 \%$ v. $24.1 \%, p=0.008) .{ }^{34} \mathrm{In}$ Canada in 2017, 15\% of DCD grafts procured never went on to be transplanted ${ }^{1}$; thus, if NMP could increase the number of these grafts that are successfully transplanted, further progress could be made to reduce wait list mortality. However, biliary complications after transplantation remain a considerable problem in DCD grafts, and Nasralla and colleagues demonstrated no statistically significant difference in IC between NMP and SCS preserved DCD liver grafts. ${ }^{34}$ Reducing IC in DCD grafts remains a major research target for NMP, but it is 
unclear whether any interventional strategies will ultimately mitigate the risk of IC.

These initial published studies using NMP have perfusion initiated at the time of procurement. This requires the donor procurement either to take place in the transplant centre with the perfusion device, or that the perfusion device be portable. Bral and colleagues have recently completed the first clinical study investigating the use of NMP following a period of SCS. ${ }^{35}$ Normothermic machine perfusion was initiated after SCS in 26 livers (6 DCD) and compared with 17 grafts (4 DCD) that had NMP initiated at the time of procurement. There was no significant difference in graft or patient survival or transaminase levels between groups. Biliary complications were also similar between groups. ${ }^{35}$ While this study included only a small number of patients, particularly for DCD grafts, it suggests that NMP can be used safely after a period of SCS without compromising outcomes. This will require further study with larger numbers of patients before being implemented more widely in clinical practice; however, as the authors point out, in Canada many procurements require air travel and therefore being able to maintain current procurement practices and then use NMP after arrival back to the transplant centre would greatly simplify the logistics of implementing this technology.

\section{Conclusion}

Donation after circulatory death liver transplantation has resulted in an increase in transplants being performed in Canada; however, discard rates are substantial, and higher rates of IC persist. Donor selection remains critical, while thrombolytic protocols have shown early benefits for graft survival and IC. Machine perfusion shows promise in both increasing use and improving outcomes; however, clinical data are still emerging, particularly for DCD grafts. Ongoing research aims to optimize machine perfusion protocols, establish reliable viability criteria and demonstrate consistent long-term outcomes before widespread clinical implementation.

Affiliations: From the Department of Surgery, Division of General Surgery, University of Alberta Hospital, Edmonton, Alta. (Nostedt, Shapiro, Bigam); the Department of Physiology, University of Alberta, Edmonton, Alta. (Freed); and the Department of Surgery, Division of Cardiac Surgery, University of Alberta, Alberta Heart Institute, Edmonton, Alta. (Freed).

Competing interests: D. Freed is a co-founder of Tevosol Inc. Tevosol had no input in the design, review or writing of this paper. No other competing interests were declared.

Contributors: J. Nostedt, J. Shapiro and D. Bigam designed the review. J. Nostedt acquired and interpreted the information collected, which D. Freed and D. Bigam also interpreted. J. Nostedt wrote the article, which all authors reviewed and approved for publication.

\section{References}

1. Canadian Institute for Health Information. Canadian Organ Replacement Register, 2017 Cumulative Report. Ottawa: CIHI; 2018. Available: https://www.cihi.ca/en/e-statistics-on-organ-transplants-waiting-lists -and-donors (accessed 2019 Jan. 9).

2. Shemie SD. Trends in deceased organ donation in Canada. CMAf 2017;189:E1204-5.

3. Foley DP, Fernandez LA, Leverson G, et al. Donation after cardiac death: the University of Wisconsin experience with liver transplantation. Ann Surg 2005;242:724-31.

4. Jay CL, Lyuksemburg V, Ladner DP, et al. Ischemic cholangiopathy after controlled donation after cardiac death liver transplantation: a meta-analysis. Ann Surg 2011;253:259-64.

5. Tang JX, Na N, Li JJ, et al. Outcomes of controlled donation after cardiac death compared with donation after brain death in liver transplantation: a systematic review and meta-analysis. Transplant Proc 2018;50:33-41.

6. Mourad MM, Algarni A, Liossis C, et al. Aetiology and risk factors of ischaemic cholangiopathy after liver transplantation. World $\mathcal{f}$ Gastroenterol 2014;20:6159-69.

7. Adkins RB Jr, Chapman WC, Reddy VS. Embryology, anatomy, and surgical applications of the extrahepatic biliary system. Surg Clin North Am 2000;80:363-79.

8. Op den Dries S, Westerkamp AC, Karimian N, et al. Injury to peribiliary glands and vascular plexus before liver transplantation predicts formation of non-anastomotic biliary strictures. 7 Hepatol 2014;60:1172-9.

9. Skaro AI, Jay CL, Baker TB, et al. The impact of ischemic cholangiopathy in liver transplantation using donors after cardiac death: the untold story. Surgery 2009; 146:543-52.

10. Mathur AK, Heimbach J, Steffick DE, et al. Donation after cardiac death liver transplantation: predictors of outcome. Am 7 Transplant 2010;10:2512-9.

11. Chan EY, Olson LC, Kisthard JA, et al. Ischemic cholangiopathy following liver transplantation from donation after cardiac death donors. Liver Transpl 2008;14:604-10.

12. Schlegel A, Scalera I, Perera M, et al. Impact of donor age in donation after circulatory death liver transplantation: Is the cutoff " 60 " still of relevance? Liver Transpl 2018;24:352-62.

13. Boteon YL, Boteon A, Attard J, et al. Ex situ machine perfusion as a tool to recondition steatotic donor livers: troublesome features of fatty livers and the role of defatting therapies. A systematic review. Am 7 Transplant 2018;18:2384-99.

14. Kalisvaart M, de Haan JE, Polak WG, et al. Comparison of postoperative outcomes between donation after circulatory death and donation after brain death liver transplantation using the comprehensive complication index. Ann Surg 2017;266:772-8.

15. Coffey JC, Wanis KN, Monbaliu D, et al. The influence of functional warm ischemia time on DCD liver transplant recipients' outcomes. Clin Transplant 2017;31: doi: 10.1111/ ctr. 13068

16. Tun-Abraham ME, Wanis $\mathrm{K}$, Garcia-Ochoa C, et al. Can we reduce ischemic cholangiopathy rates in donation after cardiac death liver transplantation after 10 years of practice? Canadian single-centre experience. Can 7 Surg 2019;62:44-51.

17. Cao Y, Shahrestani S, Chew HC, et al. Donation after circulatory death for liver transplantation: a meta-analysis on the location of life support withdrawal affecting outcomes. Transplantation 2016; 100:1513-24.

18. Lee KW, Simpkins CE, Montgomery RA, et al. Factors affecting graft survival after liver transplantation from donation after cardiac death donors. Transplantation 2006;82:1683-8.

19. Heidenhain C, Pratschke J, Puhl G, et al. Incidence of and risk factors for ischemic-type biliary lesions following orthotopic liver transplantation. Transpl Int 2010;23:14-22. 
20. Hashimoto K, Eghtesad B, Gunasekaran G, et al. Use of tissue plasminogen activator in liver transplantation from donation after cardiac death donors. Am 7 Transplant 2010;10:2665-72.

21. Seal JB, Bohorquez H, Reichman T, et al. Thrombolytic protocol minimizes ischemic-type biliary complications in liver transplantation from donation after circulatory death donors. Liver Transpl 2015;21:321-8

22. Pietersen LC, den Dulk AC, Braat AE, et al. Flushing the liver with urokinase before transplantation does not prevent nonanastomotic biliary strictures. Liver Transpl 2016;22:420-6.

23. Kubal C, Mangus R, Fridell J, et al. Optimization of perioperative conditions to prevent ischemic cholangiopathy in donation after circulatory death donor liver transplantation. Transplantation 2016;100:1699-704.

24. Bohorquez H, Seal JB, Cohen AJ, et al. Safety and outcomes in 100 consecutive donation after circulatory death liver transplants using a protocol that includes thrombolytic therapy. Am $\mathcal{F}$ Transplant 2017; 17:2155-64.

25. Jayant K, Reccia I, Virdis F, et al. Systematic review and metaanalysis on the impact of thrombolytic therapy in liver transplantation following donation after circulatory death. 7 Clin Med 2018;7 doi: $10.3390 / \mathrm{jcm} 7110425$.

26. Jones JM, Bhutiani N, Wei D, et al. A literature-based cost analysis of tissue plasminogen activator for prevention of biliary stricture in donation after circulatory death liver transplantation. Am 7 Surg 2018;216:959-62.

27. Dutkowski P, Polak WG, Muiesan P, et al. First comparison of hypothermic oxygenated perfusion versus static cold storage of human donation after cardiac death liver transplants. Ann Surg 2015;262:764-71.

28. van Rijn R, Karimian N, Matton APM, et al. Dual hypothermic oxygenated machine perfusion in liver transplants donated after circulatory death. Br 7 Surg 2017;104:907-17.

29. van Rijn R, van Leeuwen OB, Matton APM, et al. Hypothermic oxygenated machine perfusion reduces bile duct reperfusion injury after transplantation of donation after circulatory death livers. Liver Transpl 2018;24:655-64.

30. Schlegel A, Muller X, Kalisvaart M, et al. Outcomes of DCD liver transplantation using organs treated by hypothermic oxygenated perfusion before implantation. 7 Hepatol 2019;70:50-7.

31. Ravikumar R, Jassem W, Mergental H, et al. Liver transplantation after ex vivo normothermic machine preservation: a phase 1 (firstin-man) clinical trial. Am 7 Transplant 2016;16:1779-87.

32. Selzner M, Goldaracena N, Echeverri J, et al. Normothermic ex vivo liver perfusion using steen solution as perfusate for human liver transplantation: first North American results. Liver Transpl 2016;22:1501-8
33. Bral M, Gala-Lopez B, Bigam D, et al. Preliminary single-center Canadian experience of human normothermic ex vivo liver perfusion: results of a clinical trial. Am $\mathcal{F}$ Transplant 2017;17:1071-80.

34. Nasralla D, Coussios CC, Mergental H, et al. A randomized trial of normothermic preservation in liver transplantation. Nature 2018; 557:50-6.

35. Bral M, Dajani K, Leon Izquierdo D, et al. A back-to-base experience of human normothermic ex situ liver perfusion: Does the chill kill? Liver Transpl 2019;25:848-58.

36. Schlegel A, de Rougemont O, Graf R, et al. Protective mechanisms of end-ischemic cold machine perfusion in DCD liver grafts. $f$ Hepatol 2013;58:278-86.

37. Li P, Liu YF, Yang L. Advantages of dual hypothermic oxygenated machine perfusion over simple cold storage in the preservation of liver from porcine donors after cardiac death. Clin Transplant 2015;29:820-8.

38. Op den Dries S, Sutton ME, Karimian N, et al. Hypothermic oxygenated machine perfusion prevents arteriolonecrosis of the peribiliary plexus in pig livers donated after circulatory death. PLoS One 2014;9:e88521.

39. Westerkamp AC, Karimian N, Matton AP, et al. Oxygenated hypothermic machine perfusion after static cold storage improves hepatobiliary function of extended criteria donor livers. Transplantation 2016;100:825-35.

40. Minor T, Efferz P, Fox M, et al. Controlled oxygenated rewarming of cold stored liver grafts by thermally graduated machine perfusion prior to reperfusion. Am 7 Transplant 2013;13:1450-60.

41. Hoyer DP, Paul A, Luer S, et al. End-ischemic reconditioning of liver allografts: controlling the rewarming. Liver Transpl 2016;22:1223-30.

42. Hoyer DP, Mathe Z, Gallinat A, et al. Controlled oxygenated rewarming of cold stored livers prior to transplantation: first clinical application of a new concept. Transplantation 2016;100:147-52.

43. Bruinsma BG, Yeh H, Ozer S, et al. Subnormothermic machine perfusion for ex vivo preservation and recovery of the human liver for transplantation. Am 7 Transplant 2014;14:1400-9.

44. Liu Q, Nassar A, Farias K, et al. Sanguineous normothermic machine perfusion improves hemodynamics and biliary epithelial regeneration in donation after cardiac death porcine livers. Liver Transpl 2014;20:987-99.

45. Boehnert MU, Yeung JC, Bazerbachi F, et al. Normothermic acellular ex vivo liver perfusion reduces liver and bile duct injury of pig livers retrieved after cardiac death. Am $\mathcal{F}$ Transplant 2013;13:1441-9.

46. Nostedt JJ, Skubleny DT, Shapiro AMJ, et al. Normothermic ex vivo machine perfusion for liver grafts recovered from donors after circulatory death: a systematic review and meta-analysis. HPB Surg 2018; doi: 10.1155/2018/6867986. 